\title{
Production and characterisation of a monoclonal antibody to a cell-surface, glucomannoprotein constituent of Candida albicans and other pathogenic Candida species
}

\author{
A. CASSONE, A. TOROSANTUCCI, M. BOCCANERA, G. PELLEGRINI, C. PALMA and \\ F. MALAVASI*
}

Medical Mycology Unit, Istituto Superiore di Sanità, Viale Regina Elena, 29900161 -Rome and *Laboratory of Cell Biology, Università di Torino, Turin, Italy

\begin{abstract}
Summary. A murine monoclonal antibody (MAB AF-1) class IgM was raised to a soluble glucomannoprotein extract (GMP) of Candida albicans. Agglutination and indirect immunofluorescence assays with purified MAB showed that AF-1 was directed against a cell-surface epitope shared by $C$. albicans serotypes $\mathrm{A}$ and $\mathrm{B}, C$. tropicalis, $C$. guilliermondii and $C$. viswanathii, but not by $C$. krusei, $C$. parapsilosis, $C$. kefyr (pseudotropicalis) and T. glabrata. Treatment with heat, protease or periodatetreated GMP and with other cell-wall extracts of $C$. albicans provided evidence that the epitope recognised by MAB AF-1 is carried by the polysaccharide moiety of cellsurface glucomannoprotein molecule(s).
\end{abstract}

\section{Introduction}

By their unique feature of recognising single or iterative epitopes on complex antigenic structures, monoclonal antibodies (MABs) are widely used to dissect molecular structures and identify their biological functions.

Although MABs raised against different cell-wall antigens of Candida spp. have been obtained and used for diagnostic (Miyakawa et al., 1986) or physiological (Brawner and Cutler, 1984, 1986; Hopwood et al., 1986) studies, these reagents were not produced by immunisation with a soluble glucomannoprotein extract. The low intrinsic antimannoprotein humoral immune response in mice has been observed repeatedly, and Domer et al. (1986) have demonstrated that some mannoprotein from the cell wall of $C$. albicans may suppress the B-lymphocyte response. A MAB has been obtained by immunisation with a previously characterised glucomannoprotein-rich antigenic extract (GMP) from the cell wall of $C$. albicans (Ausiello et al., 1986; Scaringi et al., 1988). In this paper we describe some of the distinctive features of this new MAB.

Received 4 Mar. 1988; revised version accepted 19 May 1988.

\section{Materials and methods}

\section{Organism and growth conditions}

C. albicans, strain BP, serotype A, was from the collection of the Instituto Superiore di Sanità, Rome. Strains CA2 and A12 of $C$. albicans were agerminative variants, the origin of which has been reported elsewhere (Mattia et al., 1982). All other strains or species employed throughout the studies were isolated from patients with vaginitis (Mondello et al., 1986). The organisms were routinely maintained on Malt-extract Agar (Difco) at $28^{\circ} \mathrm{C}$. Liquid cultures were in low-glucose Winge medium, as described by Mattia and Cassone (1979). Unless otherwise stated, the experimental results refer to $C$. albicans strain BP.

\section{Cell-wall fractions}

A cell-wall mannan fraction (M) was extracted and purified as reported by Peat $e$ t al. (1961) A glucomannoprotein complex (GMP), an alkali-extracted mannan preparation (M-alk) and an alkali-acid insoluble glucan ("glucan ghosts", GG) were prepared as described by Ausiello et al. (1986) and Cassone et al. (1981). The crude chemical composition of these fractions has been reported by Ausiello et al. (1986) and Scaringi et al. (1988). In particular, polysaccharide composition was determined by gas-liquid chromatography according to the method of Albersheim et al. (1967). 


\section{Treatments of GMP}

Protease treatment. A solution of GMP $2 \mathrm{mg} / \mathrm{ml}$ in $0.1 \mathrm{M}$

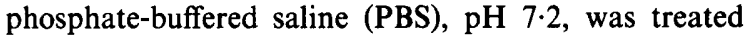
overnight at $37^{\circ} \mathrm{C}$ with Pronase (Calbiochem-Behring, La Jolla, CA) dissolved at a final concentration of $0.1 \mathrm{mg} /$ $\mathrm{ml}$ in the same buffer. The enzyme was precipitated by heating for $5 \mathrm{~min}$ at $100^{\circ} \mathrm{C}$ and the supernate dialysed against water and lyophilised. Control samples were heated in PBS only. The protein content in the samples was determined before and after the treatment by the method of Lowry et al. (1951).

Periodate oxidation. GMP was dissolved at a concentration of $1 \mathrm{mg} / \mathrm{ml}$ in $0.05 \mathrm{M}$ acetate buffer, $\mathrm{pH} 4.5$, containing $0.2 \mathrm{M} \mathrm{NaIO}_{4}$ and incubated for $18 \mathrm{~h}$ at $4^{\circ} \mathrm{C}$; at the end of the incubation period, excess periodate in the mixture was blocked by adding $1 \mathrm{ml}$ of ethylene glycol, and then the samples were extensively dialysed against water and lyophilised.

\section{Immunisation and hybridoma production}

Two female BALB/c mice (Charles River, Calco, Italy) were given subcutaneous injections at weekly intervals of $0.1 \mathrm{mg}$ of GMP (three times as a suspension in $0.25 \mathrm{ml}$ of complete Freund's adjuvant and the fourth time dissolved in $0.25 \mathrm{ml}$ of saline). The final boosting dose $(0.025 \mathrm{mg}$ in saline) was given intravenously 3 days before the fusion. Spleen cells of GMP-immunised mice were fused at a $1: 3$ ratio with myeloma cells of the murine line X63-Ag8 653 and hybrids selected and maintained as reported by Malavasi et al. (1984). Culture supernates were screened for antibody production by an ELISA technique with the immunising antigen as coating, as described by Ausiello et al. (1986). An irrelevant IgM MAB was used as a negative control and a human anti-Candida serum (HA titre 640) was the positive control for the ELISA tests (see also below). The stable, selected hybridoma was cloned twice by limiting dilution and subsequently grown in vivo in pristane-treated $B A L B / c$ mice. The ascitic fluids thus obtained were used as a massive source for MAB purification.

\section{Monoclonal antibody purification}

(i) Ammonium sulphate precipitation. MAB was precipitated by adding $\left(\mathrm{NH}_{4}\right)_{2} \mathrm{SO}_{4} 50 \% \mathrm{w} / \mathrm{v}$ to PBS-diluted ascitic fluids. The precipitates were collected by centrifugation and dialysed extensively against PBS.

(ii) Affinity chromatography. The MAB from ascitic fluids was purified on a $6.5 \mathrm{~cm} \times 0.5 \mathrm{~cm}$ column with AffPrep protein A support matrix, equilibrated with MAPS II buffers (BioRad, Richmond, USA). This support, according to the manufacturer's specifications and the personal reports of others (Mariani and Cianfriglia, I.S.S., Rome), when used in conjunction with optimised MAPS buffers, is highly efficient at binding a wide range of immunoglobulins, including murine IgM. Briefly, the column was pre-equilibrated with MAPS II buffer, $\mathrm{pH} 9.0$, then loaded with $0.5-2.0 \mathrm{ml}$ of ascitic fluid, diluted 1 in 5 in buffer, at a flow rate of $2 \mathrm{ml} / \mathrm{h}$. After washing with buffer to eliminate unbound proteins, the immunoglobulin fraction was eluted at $\mathrm{pH} 5$ and $\mathrm{pH} 3$ with $0 \cdot 1 \mathrm{M}$ citrate buffer containing $0 \cdot 15 \mathrm{M} \mathrm{NaCl}$. Fractions corresponding to protein peaks were dialysed against PBS and tested by ELISA. The yield of MAB AF-1 after this purification was around $70 \%$.

Antibody titres of ammonium sulphate-precipitated and chromatographically-purified batches of the MAB were determined as the highest dilution of the antibody that gave at least twice the absorbance value obtained in the negative control.

\section{Determination of the immunoglobulin class}

Ig class attribution of the MAB was inferred from reactivity with conjugated goat anti-mouse $\mu$ or $\gamma$ chain, and from the results of the Outcherlony test performed on affinity-purified MAB with goat anti- $\mu$ chain or anti- $\gamma$ chain specific antiserum in $0.1 \mathrm{M}$ veronal buffer, $\mathrm{pH} 8 \cdot 1$, in $1 \%$ purified agar. Sensitivity to 2 -mercaptoethanol (2ME) was determined by treating the MAB for $2 \mathrm{~h}$ at $37^{\circ} \mathrm{C}$ with $0 \cdot 1 \mathrm{M}$ 2-ME and assaying the reactivity of the treated antibody by the ELISA technique. Finally, the purified MAB was subjected to SDS-polyacrylamide gel electrophoresis (SDS-PAGE) by the method of Laemmli (1970).

\section{Immunofluorescence assay}

Drops of freshly grown, washed yeast cells were heatfixed on microscope slides at $60^{\circ} \mathrm{C}$ for $30 \mathrm{~min}$ and then allowed to react for $30 \mathrm{~min}$ at $37^{\circ} \mathrm{C}$ with affinity-purified MAB (ELISA titre 3000), diluted 1 in 5 with PBS. The smears were washed twice in PBS and the bound MAB was shown by treating for $30 \mathrm{~min}$ at $37^{\circ} \mathrm{C}$ with a 1 in 50 dilution of FITC-conjugated goat anti-mouse IgM (Sigma). Slides were mounted in $0 \cdot 2 \mathrm{M}$ carbonate buffer, pH $9 \cdot 6$, containing $90 \%$ glycerol, and examined by fluorescence microscopy (SM-LUX; Leitz, Wetzlar, Germany).

\section{Agglutination tests}

Reactivity of the MAB with different species of Candida was assessed by a slide agglutination test with either glutaraldehyde-inactivated or viable cells. The standard test was performed with yeast cells grown for $24 \mathrm{~h}$ in Winge medium at $28^{\circ} \mathrm{C}$, washed and then adjusted to a concentration of $3 \times 10^{7}$ cells $/ \mathrm{ml}$ in saline; $25 \mu \mathrm{l}$ of cell suspensions were mixed with $25 \mu$ lof the MAB at the appropriate dilution on an agglutination slide and the results assessed visually were recorded after gentle rotation of the samples for $10 \mathrm{~min}$. For absorption assays, $5 \mu \mathrm{l}$ of a suitable dilution of purified MAB was added to $100 \mu \mathrm{l}$ of a suspension containing approximately $3 \times 10^{7}$ glutaraldehyde-inactivated cells of different Candida species. The suspensions were incubated overnight at room temperature and the undiluted supernates were tested for agglutination of the Candida species as 
tested for agglutination of the Candida species as described above. No appreciable differences were observed between the agglutination of live or chemicallyinactivated cells.

\section{ELISA-inhibition tests}

Cell-wall fractions were assayed in an ELISA-inhibition test essentially as described by Ausiello et al. (1986) and Scaringi et al. (1988). Briefly, each fraction was added, at suitable concentration, to an appropriate MAB dilution and incubated overnight at room temperature. The mixtures were then added to antigen (GMP)-coated wells and the immunosorbent assay performed as previously reported (Ausiello et al., 1986). The percentage inhibition by the cell-wall fraction was calculated from the formula $\mathbf{A}_{405} \mathbf{T}-\mathbf{A}_{405} \mathbf{I} / \mathbf{A}_{405} \mathbf{T}-\mathbf{A}_{405} \mathbf{B}$, where $\mathbf{A}_{405} \mathbf{I}$ was the reading from the wells containing the putative inhibitor fraction and $\mathrm{A}_{405} \mathrm{~T}$ and $\mathrm{A}_{405} \mathrm{~B}$ the readings from the wells without inhibitor or with the fraction and the irrelevant MAB (negative control), respectively.

The ELISA tests were read with a Titertek Multiscan (Flow Laboratories, Milan, Italy) set at $405 \mathrm{~nm}$ and the blank set against air. Tests were performed in triplicate and the $\mathrm{A}_{405}$ of the well with the irrelevant MAB (usually $0 \cdot 14-0 \cdot 16$ ) was taken as the negative background reading. A positive test was one with at least twice the absorbance $\left(A_{405}\right)$ of the mean background reading. The SD values of the readings were always $<0.01 \%$ and have been omitted from the results.

\section{Results}

\section{Hybridoma production, $M A B$ secretion and purification}

Splenocytes from a mouse immunised with $C$. albicans GMP were fused with cells of the murine myeloma line X63-Ag8.653. After 14 days, 2 wells out of 384 in which cells had grown gave positive results in the ELISA tests with GMP as solid-phase antigen. One of the two selected primary cultures gave rise to a stable hybridoma which, after cloning and propagation into pristane-treated mice, was used as the source of the MAB (hereafter referred to as MAB AF-1). The MAB from the ascitic fluid was partially purified by ammonium-sulphate precipitation and affinity chromatography. The MAB was sensitive to 2-mercaptoethanol treatment. Moreover, indirect ELISA binding with anti-mouse IgM, Ouchterlony tests, and SDS-PAGE showed that MAB AF-1 belonged to the IgM class (data not shown).

Slide agglutination assay with glutaraldehydeinactivated or viable yeast cells showed that MAB AF-1 had strong agglutination properties (table I), and agglutinated all the isolates of $C$. albicans serotypes $\mathrm{A}$ and $\mathrm{B}, C$. tropicalis, $C$. guilliermondii and $C$. viswanathii that were tested but did not agglutinate $T$. glabrata, $C$. krusei, $C$. parapsilosis or C. kefyr.

Two agerminative isolates of $C$. albicans were also agglutinated by MAB AF-1 to an extent not visibly different from that of the germinative isolates. Table I also shows the antigenic formula of the species tested for agglutination with polyclonal sera (Tsuchiya et al., 1984). The pattern of cell agglutination by MAB AF-1 does not indicate an obvious sharing of any of the antigenic factors considered in the formulation. Absorption of MAB AF-1 with cells of any of the agglutinated species completely abolished the reactivity with all of them,

Table I. Slide agglutination reactivity of $C$. albicans and related species with MAB AF-1*

\begin{tabular}{|c|c|c|c|c|}
\hline \multirow[b]{2}{*}{ Species } & \multirow[b]{2}{*}{$\begin{array}{l}\text { Number of } \\
\text { isolates tested }\end{array}$} & \multicolumn{2}{|c|}{ Agglutination (number positive/number tested) $\dagger$ with } & \multirow[b]{2}{*}{$\begin{array}{l}\text { Antigenic } \\
\text { formula } \ddagger\end{array}$} \\
\hline & & $\begin{array}{l}\text { Ammonium sulphate- } \\
\text { precipitated MAB }\end{array}$ & $\begin{array}{l}\text { Affinity chromatography-purified } \\
\text { MAB }\end{array}$ & \\
\hline C. albicans serotype A & 9 & $4 / 4$ & $5 / 5$ & $1,4,5,6$ \\
\hline $\begin{array}{l}\text { C. albicans serotype } \mathrm{A} \\
\text { (agerminative isolates) }\end{array}$ & 2 & N.D. & $2 / 2$ & $1,4,5,6$ \\
\hline C. albicans serotype B & 5 & $3 / 3$ & $2 / 2$ & $1,4,5,13 b$ \\
\hline C. tropicalis & 10 & $4 / 4$ & $6 / 6$ & $1,4,5,6$ \\
\hline C. parapsilosis & 9 & $0 / 3$ & $0 / 6$ & $1,5,13,13 b$ \\
\hline C. guilliermondii & 5 & $1 / 1$ & $4 / 4$ & $1,4,9$ \\
\hline C. glabrata & 10 & $0 / 4$ & $0 / 6$ & $1,4,6,34$ \\
\hline C. keyfr (pseudotropicalis) & 7 & $0 / 4$ & $0 / 3$ & 1,8 \\
\hline C. krusei & 10 & $0 / 4$ & $0 / 6$ & $1,5,11$ \\
\hline C. viswanathii & 1 & N.D. & $1 / 1$ & $1,4,6,13 b$ \\
\hline
\end{tabular}

* A standard slide agglutination assay with freshly prepared suspension of live cells and a 1 in 25 dilution of a MAB solution with an ELISA titre of 32000.

+ Different isolates were used for each MAB preparation to reach the total number of isolates reported in the second column.

$\ddagger$ According to Tsuchiya et al. (1984). 
whereas repeated absorptions of the MAB with cells of each of the non-agglutinated strains did not reduce significantly the extent of clumping of each agglutinable species.

Only those species that were agglutinated by MAB AF-1 gave positive results in an indirect immunofluoresence assay performed with purified MAB and FITC-labelled goat anti-mouse IgM serum. Fig. 1 shows an example of this reaction.

\section{Specificity of $M A B A F-1$}

To determine the chemical nature of the epitope recognised by MAB $A F-1$, the reactivity of the MAB with different $C$. albicans cell-wall-based fractions was investigated with two distinct ELISA tests that were specially devised. The first was based
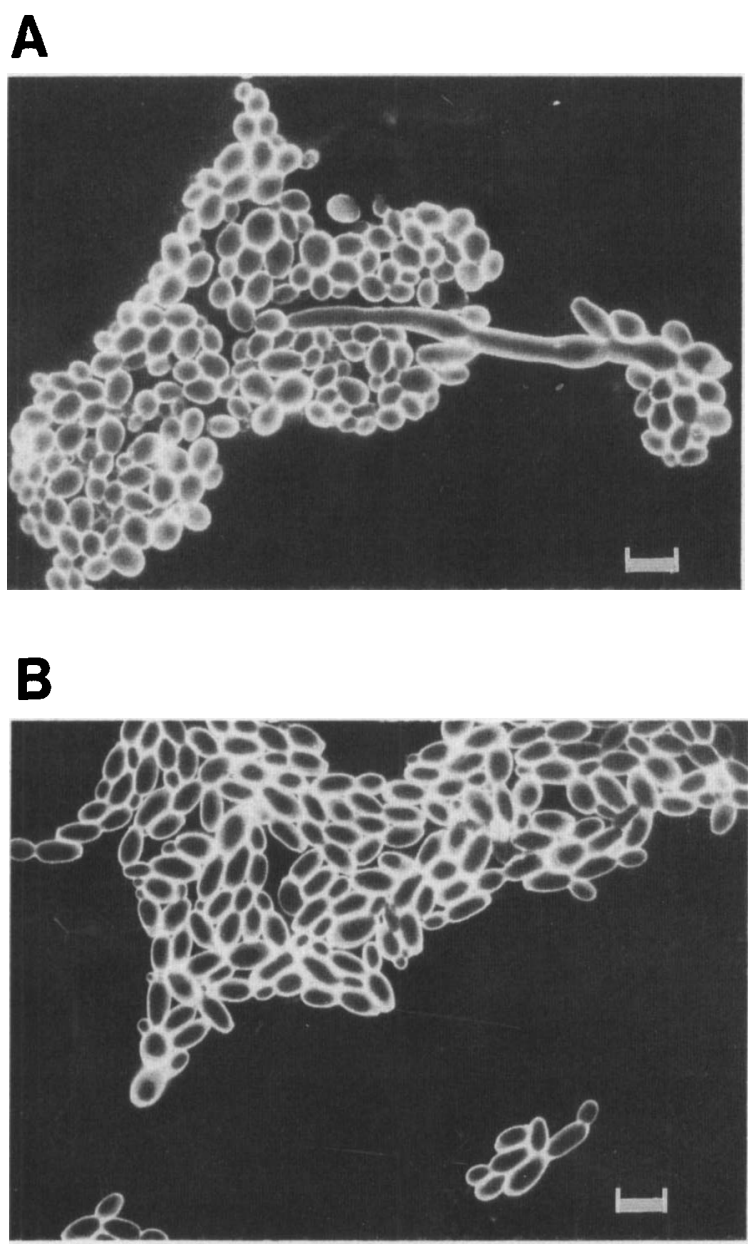

Fig. 1. Indirect immunofluorescence staining of $C$. albicans (strain BP, panel A and strain CA2, panel B) with MAB AF-1. $A$ dilution of 1 in 5 from a batch of affinity-purified MAB (ELISA titre 3000) was used for both tests. Bar $=10 \mu \mathrm{m}$. on a direct binding of the MAB with each fraction used as coating antigen; in the second, an inhibition ELISA test was performed with GMP antigen as the solid-phase reagent and each tested fraction as a free-phase, MAB AF-1 ligand in a competition reaction with GMP. This double approach was necessary because of the potential inability of some of the fractions to adsorb effectively to the plastic of the well. Data in table II show that MAB AF-1 reacted specifically with all mannan-based fractions from $C$. albicans, but not with mannan extracts from $S$. cerevisiae. The highest reactivity was apparent with a low-protein mannan extracted by the method of Peat et al. (1961), whereas the weakest reaction was with an alkali-extracted cellwall mannan (M-alk). Table II also shows that periodate oxidation abolished the reactivity of GMP with MAB AF-1, whereas GMP deproteination by pronase or heat treatment ${ }^{-1 i d}$ not greatly affect the structure of the epitope targeted by MAB $A F-1$. It should be noted that pronase-treated GMP was not effective as a coating antigen but its reaction with the $\mathrm{MAB}$ was easily evidenced in the ELISA-inhibition assay. Finally, the MAB did not react with a $\beta$-glucan preparation (GG).

The results of the ELISA tests were fully confirmed by immuno-diffusion which showed that MAB AF-1 formed readily visible precipitin lines of identity with the mannan-rich fractions of $C$. albicans but not with glucan or periodate-treated antigen (fig. 2).

\section{Discussion}

In this study, an agglutinating and precipitating murine monoclonal antibody (MAB AF-1) of the IgM class was obtained after immunisation with a glucomannoprotein extract from the cell wall of $C$. albicans (Ausiello et al., 1986). MABs directed against cell-wall antigens of this micro-organism have been reported but, generally, undefined extracts, cell walls, or heat-killed or otherwise inactivated whole cells were used as immunogens (Brawner and Cutler, 1984; Chardès et al., 1986; Miyakawa et al., 1986; Calderone et al., 1988). In one case (Hopwood et al., 1986), the MAB was obtained from an interspecific fusion between mouse myeloma cells and splenocytes of Candidainfected rats. Because it belongs to the IgM class as well as having precipitating and agglutinating properties, MAB AF-1 resembles most of the aforementioned MABs to cell surface determinants of C. albicans. However, MAB AF-1 shows a distinctive specificity. In fact, the panel of the species agglutinated by MAB AF-1, including $C$. albicans 
Table II. Indirect ELISA and ELISA-inhibition tests with MAB AF-1 and cell-wall extracts of $C$. albicans

\begin{tabular}{|c|c|c|c|c|c|}
\hline \multirow[b]{3}{*}{ Fraction } & \multirow{3}{*}{$\begin{array}{l}\text { Main sugar } \\
\text { component }^{*} \\
\text { (percentage of } \\
\text { dry weight) }\end{array}$} & \multicolumn{4}{|c|}{$\mathrm{A}_{405}$ in ELISA tests $†$} \\
\hline & & \multicolumn{2}{|c|}{$\begin{array}{l}\text { A. Fraction used as coating antigen at } \\
\text { a MAB dilution of }\end{array}$} & \multicolumn{2}{|c|}{$\begin{array}{l}\text { B. Fraction used as inhibitor at a } \\
\text { concentration of }\end{array}$} \\
\hline & & 10000 & 20000 & $0.5 \mu \mathrm{g} / \mathrm{ml}$ & $0.1 \mu \mathrm{g} / \mathrm{ml}$ \\
\hline None & - & $0 \cdot 10$ & $0 \cdot 10$ & \multicolumn{2}{|c|}{$0 \cdot 65$} \\
\hline GMP & mannose $(83 \cdot 7)$ & 0.59 & $0 \cdot 29$ & $0 \cdot 23(89.4)$ & $0.50(31.9)$ \\
\hline M & mannose $(95.8)$ & 0.92 & 0.52 & \multicolumn{2}{|c|}{ N.D. } \\
\hline M-alk & mannose $(66 \cdot 6)$ & $0 \cdot 32$ & $0 \cdot 24$ & $0 \cdot 46(39 \cdot 6)$ & $0.59(12.5)$ \\
\hline GG & glucose $(93 \cdot 1)$ & $0 \cdot 14$ & $0 \cdot 11$ & $0.65(0)$ & N.D. \\
\hline $\begin{array}{l}\text { Pronase and heat- } \\
\text { treated GMP }\end{array}$ & mannose $(61 \cdot 9)$ & $0 \cdot 10$ & $0 \cdot 10$ & $0 \cdot 34(63 \cdot 3)$ & $0 \cdot 50(30 \cdot 6)$ \\
\hline Heat-treated GMP & mannose $(72 \cdot 0)$ & $0 \cdot 49$ & $0 \cdot 27$ & $0 \cdot 38(57 \cdot 4)$ & $0.58(14.9)$ \\
\hline Periodate-treated GMP & N.D. & $0 \cdot 11$ & $0 \cdot 10$ & $0 \cdot 64(2 \cdot 1)$ & $0.65(0)$ \\
\hline
\end{tabular}

N.D. = not done. ${ }^{*}$ Determined by gas-liquid chromatography.

$\dagger$ Tests $A$ and $B$ were performed independently. In A, each fraction was used as coating (solid phase) antigen at a concentration of $5 \mu \mathrm{g} / \mathrm{ml}$. In the inhibition test B, MAB AF-1 was used at a dilution (1 in 10000$)$ giving the indicated absorbance reading in the uninhibited control (first line). Values in brackets represent the percentage inhibition. Three experiments were performed, with similar results; the ELISA values reported are those from one of these experiments. For other details, see Materials and methods.

serotypes A and B, C. tropicalis and C.guilliermondii, does not correspond to any of the major Candida groups in the serological classification scheme of Tsuchiya et al. (1984). On the contrary, MABS previously reported as anti-cell-wall reagents reacted with epitopes largely overlapping with major determinants (e.g., factors 4 and 5) of Tsuchiya's
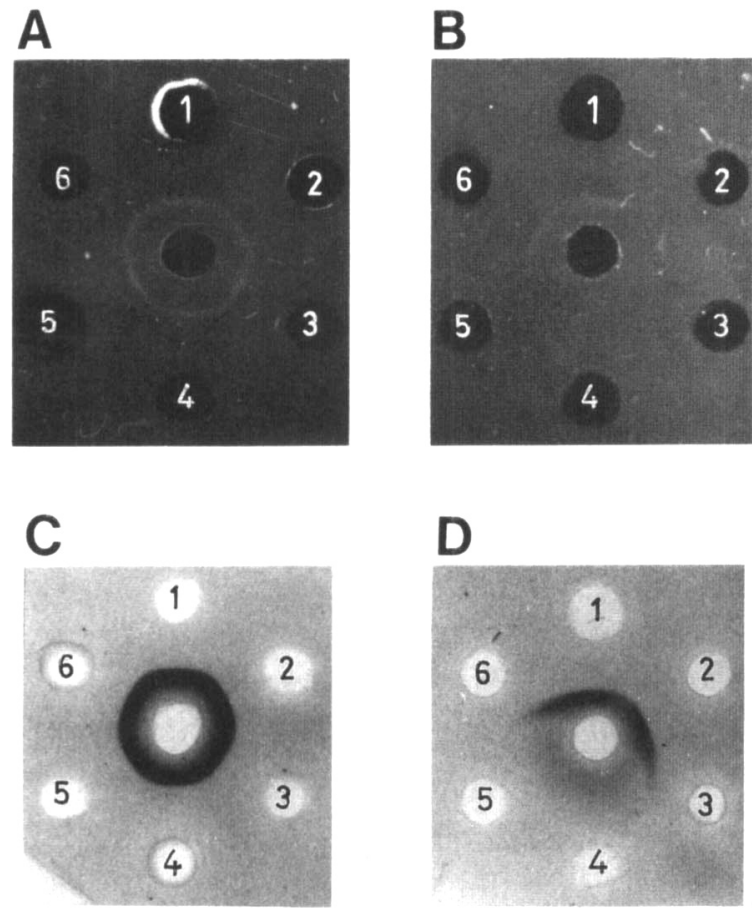

classification. Moreover, the epitope recognised by MAB AF-1 was also present in C. viswanathii, a pathogenic Candida species that was not tested for its reactivity with previous MABs.

The experiments involving cell-wall fractions and modified antigens of $C$. albicans consistently demonstrated that the determinant recognised by MAB AF-1 is part of a cell-wall polysaccharideprotein component, probably a mannoprotein, with the specific epitope being a piece of the polysaccharide moiety. Apart from its reactivity with the mannoprotein-rich extract (GMP) used for immunisation and antibody screening, MAB AF-1 also reacted with all other $C$. albicans mannan fractions tested, one of which (M) was extracted by a procedure yielding a mannan with very little protein. The MAB reacted poorly with an alkaliextracted mannoprotein constituent (M-alk) but

Fig. 2. Ouchterlony tests with affinity-purified MAB AF-1 in central wells (ELISA titre $16000,20 \mu \mathrm{l}$ ) and antigenic fractions in the peripheral wells. Each fraction was used as a concentration of $2 \mathrm{mg} / \mathrm{ml}$ in a volume of $20 \mu \mathrm{l} /$ well. Panels A and B show unstained preparations, panels $C$ and $D$ show tests performed as above but stained with Coomassie blue $(0.1 \%$ in methanol $50 \%$ and acetic acid $10 \%$ ). $\mathbf{A}$ and $\mathrm{C}: 1,2$ and 6 represent GMP from three independent batches; 3 , pronase and heat-treated GMP ; 4, heat-treated GMP ; 5, M. B: 1, GMP ; 2, GG ; 3 and 4, periodate-treated GMP (two independent preparations); 5, GMP from $S$. cerevisiae; 6, M-alk. D: 1, GMP; 2, M-alk; 3 and 4, periodate treated GMP (two independent preparations); 5 , GMP from C. cerevisiae; 6 , GG. 
did not react at all with an insoluble glucan constituent of the cell wall (GG). GMP ability to bind MAB AF-1 was not lost after heat or pronaseplus-heat treatment whereas it was highly sensitive to periodate oxidation, as expected of a carbohydrate epitope.

Previous studies (Ausiello et al., 1986; Scaringi et al., 1988) have shown that the polysaccharide component of GMP contained mannose and glucose (in a ratio of about 30:1). The cell-surface antigens of $C$. albicans identified by MABs $\mathrm{H} 9$ and C6 of Brawner and Cutler $(1984,1986)$ were also

\section{REFERENCES}

Albersheim P, Nevins D J, English P D, Karr A 1967 A method for the analysis of sugars in plant cell-wall polysaccharides by gas-liquid chromatography. Carbohydrate Research 5: 340-345.

Ausiello C M et al. 1986 Proliferation of human peripheral blood mononuclear cells induced by Candida albicans and its cell wall fractions. Journal of Medical Microbiology 22: 195-202.

Brawner D L, Cutler J E 1984 Variability in expression of a cell surface determinant on Candida albicans as evidenced by an agglutinating monoclonal antibody. Infection and Immunity 43: 966-972.

Brawner D L, Cutler J E 1986 Ultrastructural and biochemical studies of two dynamically expressed cell surface determinants on Candida albicans. Infection and Immunity 51 : 327 336.

Calderone R A, Linehan L, Wadsworth E, Sandberg A L 1988 Identification of C $3 \mathrm{~d}$ receptors on Candida albicans. Infection and Immunity 56: 252-258.

Cassone A et al 1981 Immunoadjuvant effects of Candida albicans and its cell wall fractions in a mouse lymphoma model. Cancer Immunology and Immunotherapy 10: 181-190.

Chardès T., Piechaczyk M, Cavaillès V, Salhi S L, Pau B, Bastide J M 1986 Production and partial characterisation anti-Candida monoclonal antibodies. Annales de L'Institut Pasteur/Immunologie 137C: 117-125.

Domer J E, Stashak P W, Elkins K, Prescott B, Caldes G, Baker P J 1986 Separation of immunomodulatory effects of mannan from Candida albicans into stimulatory and suppressive components. Cellular Immunology 101: 403414.

Hopwood V, Poulain D, Fortier B, Evans G, Vernes A 1986 A monoclonal antibody to a cell wall component of Candida albicans. Infection and Immunity 54 : 222-227.

Laemmli V K 1970 Cleavage of structural proteins during the assembly of the head of bacteriophage T4. Nature 227: 680 685 . polysaccharide in nature but with a much lower mannose : glucose ratio.

The overall evidence obtained so far suggests that MAB AF-1 identifies a new polysaccharide epitope of the cell wall of some pathogenic Candida species.

The authors acknowledge financial support of grants from CNR (Italy) Contract Nos. 860260.44 and 8601563.52 within the Projects "Oncologia" and "Controllo delle Malattie Infettive", respectively.

Lowry O H, Rosenbrough N J, Farr A L, Randall R J 1951 Protein measurement with the Folin phenol reagent. Journal of Biological Chemistry 193: 265-275.

Malavasi F, Caligaris-Cappis F, Milanese C, Della Bona P, Richiardi P, Carbonara A O 1984 Characterisation of a murine monoclonal antibody specific for human early lymphohemapoietic cells. Human Immunology 9: 9-20.

Mattia E, Cassone A 1979 Inducibility of a germ-tube formation in Candida albicans at different phases of yeast growth. Journal of General Microbiology 113: 439-442.

Mattia E, Carruba G, Angiolella L, Cassone A 1982 Induction of germ-tube formation by $\mathrm{N}$-acetyl-D-glucosamine in Candida albicans: uptake of the inducer and germinative response. Journal of Bacteriology 152: 555-562.

Miyakawa Y, Kagaya K, Fukazawa Y, Soe G 1986 Production and characterisation of agglutinating monoclonal antibodies against predominant antigenic factors for Candida albicans. Journal of Clinical Microbiology 23: 881-886.

Mondello F, Guglielminetti M, Torosantucci A, Ceddia T, Agatensi L, Cassone A 1986 Yeast species isolated from outpatient with vulvovaginal candidosis attending a gynecological centre in Rome. IRCS Medical Science 14: 746747.

Peat S, Whelan W J, Edwards T E 1961 Polysaccharides of baker's yeast. IV. Mannan. Journal of the Chemical Society 1: $29-34$.

Scaringi L, Marconi P, Boccanera M, Tissi L, Bistoni F, Cassone A 1988 Cell wall components of Candida albicans as immunomodulators: induction of natural killer and macrophage-mediated peritoneal cells cytotoxicity in mice by mannoprotein and glucan fractions. Journal of General Microbiology 134: 1265-1274.

Tsuchiya T, Taguchi M, Fukazawa Y, Shinoda T 1984 Serological characterisation of yeasts as an aid in identification and classification. In: Bergan $T$ (ed) Methods in microbiology vol 16. Academic Press, Inc., London, pp 75126. 